\title{
Multi objective optimization for kerf and material removal rate in wire electrical discharge machining using Taguchi method combined grey relational analysis
}

\author{
Pathya Rupajati ${ }^{1, *}$, M. Kurniadi Rasyid ${ }^{1}$ and Ali Nurdin $^{2}$ \\ ${ }^{1}$ Mechanical Engineering Department, Institut Teknologi Indonesia, 15314 Tangerang Selatan, \\ Indonesia \\ ${ }^{2}$ BPPT BT Meppo, 15314 Kawasan Puspiptek Tangerang Selatan, Indonesia
}

\begin{abstract}
This paper investigated the multi performance characteristics of wire electrical discharge machining for an optimal machining parameters to get low kerf and high material removal rate at the same time. The machining parameters i.e arc on time, on time, servo voltage and wire feed were used in this experiment. Based on $\mathrm{L}_{9}$ orthogonal array, the signal-to-noise $(\mathrm{S} / \mathrm{N})$ ratio and the analysis of variance (ANOVA) was used to study the machining parameters of DIN 1.2510 tool steel. Multi response characteristics were solved by Taguchi method combined grey relational analysis. Experimental results are provided to demonstrate the effectiveness of this method i.e. kerf decreased from $354 \mu \mathrm{m}$ to $345 \mu \mathrm{m}$, while material removal rate (MRR) increased from $9,313 \mathrm{~mm}^{3} / \mathrm{min}$ to $13,989 \mathrm{~mm}^{3} / \mathrm{min}$. From the optimization result validated in the confirmation experiment the machining parameters combination that could produce the optimum responses are arc on time of $2 \mathrm{~A}$, pulse on time of $8 \mu \mathrm{s}$, servo voltage $80 \mathrm{~V}$ and wire feed $60 \mathrm{~mm} / \mathrm{min}$.
\end{abstract}

\section{Introduction}

The process of wire dielectrical discharge machining is a thermo-electric non conventional machining process based on the erosion due to electric sparks to produce complex shapes, accurate and precision using brass wire electrode [1]. Wire EDM is used on materials that are conductive with varying hardness and high precision to make workpieces such as tools, punch and dies. In wire-EDM, kerf (gap of width) and material removal rate (MRR) is two of the most significant performance. Goyal [2] has investigated the effect of tool electrode, current density, pulse on time, pulse off time, wire feed and wire tension during the wire electrical discharge machining of Inconel 625. It was suggested that the most significant factors that influence maximum material removal rate and surface roughness are current, pulse on time, cryogenic treated tool electrode. The wire electrical discharge machining can

*Corresponding author: pathyarupajati@gmail.com 
be used for advanced ceramics such as bismuth ferrite, barium titanate, $\mathrm{Al}_{2} \mathrm{O}_{3}, \mathrm{Ti}_{3} \mathrm{SiC}_{2}$ ceramic [3-6]. Bobbili et al.[7] reported a comparison study was conducted for the aluminium alloy 7017 and rolled homogeneous armour steel in wire-EDM, and the result presents that the increase of pulse on time affected material removal rate significantly for both materials. T.R. Newton et al. [8] have examined the effect machining parameter wireEDM of recast layer in inconel 718. Taguchi method has been widely used for optimization of a single performance characteristic [9-10]. The material removal rate (MRR), surface roughness and kerf in wire-EDM of D2 tool steel using Taguchi's $\mathrm{L}_{18}$ orthogonal array was analyzed by Ikram et al [11]. The existance of method such as fuzzy logic, grey fuzzy logic and grey relational analysis make Taguchi method can be used to optimize of multiple responses simultaneously. Deng [12] established the theory systems of grey in 1982. It helps to solve complexed interrelationship among multi objective performance characteristics successfully. Balasubramanian et al. [13] optimized surface roughness and material removal rate width using Taguchi method and grey relational grade with Taguchi's $\mathrm{L}_{8}$ orthogonal array. This paper studies wire-EDM of DIN 1.2510 steel and optimize two characteristics performance, i.e. kerf and material removal rate using Taguchi combined grey relational analysis. The characteristic quality of kerf is smaller the better and material removal rate is having higher the better.

\section{Experimental methods}

The experimental studies were performed on a CHMER CW 32GS wire electrical discharge machine tool. This experiment used DIN 1.2510 tool steel as a workpiece material with size $300 \mathrm{~mm} \times 130 \mathrm{~mm}$ x $40 \mathrm{~mm}$. Brass wire with diameter $0,25 \mathrm{~mm}$ was used as an electrode. The selected machining parameters with different level have been represented in Table 1 . Based on Taguchi method, an $\mathrm{L}_{9}$ orthogonal array was selected in this experiment was represented in Table 2. The kerf was measured by Euromex Microscope. The experiment order was run randomly with two replications to gain good validity and accuracy.

Table 1. The machining parameters and their levels.

\begin{tabular}{|c|c|c|c|}
\hline Machining parameters & Level 1 & Level 2 & Level 3 \\
\hline Arc on time $(\mathrm{A})$ & 2 & 3 & 4 \\
\hline Pulse on time $(\mu \mathrm{s})$ & 4 & 6 & 8 \\
\hline Servo voltage $(\mathrm{V})$ & 80 & 90 & 100 \\
\hline Wire Feed $(\mathrm{mm} / \mathrm{min})$ & 45 & 60 & 75 \\
\hline
\end{tabular}

Table 2. The experimental layout using orthogonal array L9.

\begin{tabular}{|c|c|c|c|c|}
\hline No & AN & ON & SV & WF \\
\hline 1 & 2 & 5 & 37 & 3 \\
\hline 2 & 2 & 7 & 55 & 7 \\
\hline 3 & 2 & 8 & 70 & 12 \\
\hline 4 & 4 & 5 & 55 & 12 \\
\hline 5 & 4 & 7 & 70 & 3 \\
\hline 6 & 4 & 8 & 37 & 7 \\
\hline 7 & 5 & 5 & 70 & 7 \\
\hline 8 & 5 & 7 & 37 & 12 \\
\hline 9 & 5 & 8 & 55 & 3 \\
\hline
\end{tabular}




\section{Results and discussion}

\subsection{Calculation signal to noise ratio $(\mathrm{S} / \mathrm{N})$ ratio}

The experimental result and signal to noise $(\mathrm{S} / \mathrm{N})$ ratio of MRR and kerf has shown in Table 3. The signal to noise ratio is a measure of the data set relative to the standard deviation. If the $\mathrm{S} / \mathrm{N}$ is small, then the magnitude is small relative to the noise, as measured using the standard deviation. There are three $\mathrm{S} / \mathrm{N}$ ratio, depending on the type ot the performance characteristics, i.e the smaller the better, higher the better, and nominal the better. In wire EDM lower the better of kerf is indications better performance, while MRR higher the better is indications better performance as equation:

Smaller the better :

$$
S / N=-10 \log \sum_{i=1}^{n} \frac{y_{i 2}}{n}
$$

Larger the better :

$$
S / N=-10 \log \left[\sum_{i=1}^{n} \frac{1 / y_{i} 2}{n}\right]
$$

where $\mathrm{n}$ is the number of measurements, and $y_{i}^{2}$ is the measured characteristic value. Regardless of the category of performance characteristics, the greater $\mathrm{S} / \mathrm{N}$ ratio corresponds to the better performance characteristics.

Table 3. The experimental result and $\mathrm{S} / \mathrm{N}$ ratio

\begin{tabular}{|c|c|c|c|c|c|c|c|c|}
\hline $\begin{array}{c}\text { No. } \\
\text { Exp }\end{array}$ & AN & ON & SV & WF & $\begin{array}{c}\text { Kerf } \\
(\mu \mathrm{m})\end{array}$ & S/N Kerf & $\begin{array}{c}\text { MRR } \\
\left(\mathrm{mm}^{3} / \mathrm{min}\right)\end{array}$ & $\begin{array}{c}\text { S/N } \\
\text { MRR }\end{array}$ \\
\hline 1 & 2 & 5 & 37 & 3 & 359 & $-51,1019$ & 10,209 & 20,179 \\
\hline 2 & 2 & 7 & 55 & 7 & 367 & $-51,2933$ & 12,728 & 22,095 \\
\hline 3 & 2 & 8 & 70 & 12 & 373 & $-51,4342$ & 8,213 & 18,290 \\
\hline 4 & 4 & 5 & 55 & 12 & 342 & $-50,6805$ & 9,913 & 19,924 \\
\hline 5 & 4 & 7 & 70 & 3 & 357 & $-51,0534$ & 7,747 & 17,782 \\
\hline 6 & 4 & 8 & 37 & 7 & 380 & $-51,5957$ & 14,853 & 23,437 \\
\hline 7 & 5 & 5 & 70 & 7 & 370 & $-51,364$ & 6,133 & 15,753 \\
\hline 8 & 5 & 7 & 37 & 12 & 347 & $-50,8066$ & 13,013 & 22,287 \\
\hline 9 & 5 & 8 & 55 & 3 & 371 & $-51,3875$ & 10,575 & 20,485 \\
\hline
\end{tabular}

\subsection{Grey Relational Analysis}

Since Taguchi method is only able to optimize single response performance characteristics, then the grey relational analysis optimizes multi performance characteristics. Furthermore, the optimization using Taguchi combined grey relational analysis able to identify the most significant parameter process wire-EDM that influence kerf and material removal rate. The optimization using grey relational analysis is done in the following three steps.

1st step. Normalization of kerf and material removal rate

The characteristics quality of kerf smaller the better which equation as follows:

$$
X i *(k)=\frac{\max X i(k)-X i(k)}{\max X i(k)-\min X i(k)}
$$

The characteristics quality of material removal rate is higher the better which equation as follows: 


$$
X i *(k)=\frac{X i(k)-\min X i(k)}{\max X i(k)-\min X i(k)}
$$

Where $X i^{*}(k)$ and $X i(k)$ are normalized data and observed data for $i$ th experiment by using $k$ th response.

2nd steps. Calculating grey relational coefficient (GRC). The grey relational coefficient can be calculated by using equation 5 .

$$
\xi i(k)=\frac{\Delta \min +\xi \Delta \max }{\Delta 0, i(k)+\xi \Delta \max }
$$

Where $\Delta_{0, i}(k)=/ / X_{0}(k)-X_{i}(k) / /$ is deviation sequence (the difference of absolute value between $X_{0}(k)$ and $X_{i}(k) ; \zeta$ the distinguishing coefficient $\in[0,1] ; \Delta_{\min }=\forall j^{\text {min }} \in i \forall k^{\min } / / X_{0}(k)$ - $X_{j}(k) / /$ is the minimum value of $\Delta_{0, i}$; and $\Delta_{\max }=\forall j^{\max } \in i \forall k^{\max } / / X_{0}(k)-X_{j}(k) / /$ is the maximum value of $\Delta_{0, i}$.

3rd step, the value of grey relational grade (GRG) is calculated by determining the average of the grey relational coefficient corresponding to each performance analysis. The equation for determining grey relational grade can be calculated as follows:

$$
\dot{r}=\frac{1}{n} \sum_{k=1}^{n} \xi(k)
$$

Where $\gamma_{i}$ is the grey relational grade and $n$ is the number of process response. Hence, grey relational grade can be used to select optimal and machining parameters. The optimal value of the GRG can be computed by using equation:

$$
\gamma_{e}=\gamma_{m}+\sum_{i=1}^{q}(\overline{\gamma i}-\gamma m)
$$

Where $\gamma_{\mathrm{m}}$ is total mean of GRG; $\mathrm{q}$ is number of input machining parameters; $\bar{\gamma}_{i}$ is mean of GRG value at the optimal level. The result of normalization, deviation sequence, GRC of kerf and MRR and GRG is shown in Table 5.

Table 4. The results of GRG

\begin{tabular}{|c|c|c|c|c|c|c|c|}
\hline \multirow{2}{*}{$\begin{array}{c}\text { No. } \\
\text { Exp }\end{array}$} & \multicolumn{2}{|c|}{ Normalization } & \multicolumn{2}{|c|}{ Deviation Sequence } & \multicolumn{2}{c|}{ GRC } & \multirow{2}{*}{ GRG } \\
\cline { 2 - 7 } & Xi*Kerf & Xi*MRR & $\Delta$ Kerf & $\Delta$ MRR & Kerf & MRR & \\
\hline 1 & 0,4604 & 0,5761 & 0,5396 & 0,4239 & 0,4810 & 0,5412 & 0,5111 \\
\hline 2 & 0,6696 & 0,8255 & 0,3304 & 0,1745 & 0,6021 & 0,7412 & 0,6717 \\
\hline 3 & 0,8235 & 0,3302 & 0,1765 & 0,6698 & 0,7391 & 0,4274 & 0,5833 \\
\hline 4 & 0,0000 & 0,5429 & 1,0000 & 0,4571 & 0,3333 & 0,5224 & 0,4279 \\
\hline 5 & 0,4074 & 0,2641 & 0,5926 & 0,7359 & 0,4576 & 0,4046 & 0,4311 \\
\hline 6 & 1,0000 & 1,0000 & 0,0000 & 0,0000 & 1,0000 & 1,0000 & 1,0000 \\
\hline 7 & 0,7469 & 0,0000 & 0,2531 & 1,0000 & 0,6639 & 0,3333 & 0,4986 \\
\hline 8 & 0,1378 & 0,8504 & 0,8622 & 0,1496 & 0,3670 & 0,7697 & 0,5684 \\
\hline 9 & 0,7725 & 0,6159 & 0,2275 & 0,3841 & 0,6873 & 0,5656 & 0,6264 \\
\hline
\end{tabular}

Based on Table 6 and Figure 1, the optimum setting of the machining process parameters is found to the experimental run no. 9, arc on time at level 1 (2 A), pulse on time at level 3 ( 8 $\mu \mathrm{s})$, servo voltage at level $1(80 \mathrm{~V})$, and wire feed at level $2(60 \mathrm{~mm} / \mathrm{min})$. The use of these conditions will minimize kerf and maximize MRR at the same time. 
Table 5. The response table for the $\mathrm{S} / \mathrm{N}$ ratio of GRG

\begin{tabular}{|c|c|c|c|c|c|}
\hline & level 1 & level 2 & level 3 & Max-Min & Rank \\
\hline Arc on time $(\mathrm{A})$ & $-4,657$ & $-4,894$ & $-5,005$ & 0,348 & 4 \\
\hline Pulse on time $(\mu \mathrm{s})$ & $-6,416$ & $-5,224$ & $-2,915$ & 3,501 & 1 \\
\hline Servo voltage $(\mathrm{V})$ & $-3,579$ & $-4,964$ & $-6,012$ & 2,433 & 3 \\
\hline Wire Feed $(\mathrm{mm} / \mathrm{min})$ & $-5,734$ & $-3,167$ & $-5,655$ & 2,567 & 2 \\
\hline
\end{tabular}

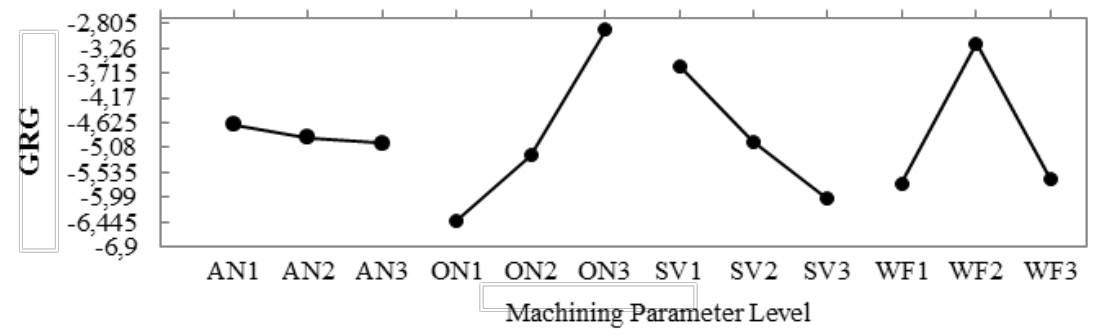

Fig. 1. Grey Relational Grade (GRG) Graph

The analysis of variance (ANOVA) is used to determine significant machining parameters which influence the multi performance characteristics and the percentage contribution of each machining parameters on the responses [14]. Due to very small difference between variances of arc on time, on time, servo voltage and wire feed, no single factor can be integrated as a non influential factors [15]. Thus, ANOVA takes directly the proportion of each sum of squares of the factor effect vector $\left(\mathrm{SS}_{\mathrm{factor}}\right)$ as the sum of squares of the total variation vector $\left(\mathrm{SS}_{\text {total }}\right)$ as a reference degree of contribution. The most influence process parameters for the GRG in order are on time, wire feed, servo voltage and arc on time. Table 7 presents the analysis of variance of GRG.

Table 6. The analysis of variance (ANOVA) of GRG

\begin{tabular}{|c|c|c|c|c|c|}
\hline Source & DF & SS & MS & F & \%contribution \\
\hline Arc on time & 2 & 0,19 & 0,09498 & $*$ & 0,46 \\
\hline On time & 2 & 19,0115 & 9,50574 & $*$ & 46,46 \\
\hline Servo voltage & 2 & 8,9337 & 4,46687 & $*$ & 21,83 \\
\hline Wire Feed & 2 & 12,7816 & 6,39082 & $*$ & 31,24 \\
\hline Residual Error & 0 & - & - & & \\
\hline Total & 8 & 40,9168 & & & \\
\hline
\end{tabular}

The predicted GRG using the optimal level of machining parameters can be calculated by equation 7. Table 8 shows the confirmation experiment of kerf and MRR using the machining parameters. As shown Table 8 , kerf is minimized from $354 \mu \mathrm{m}$ to $345 \mu \mathrm{m}$, MRR is increased from $9,131 \mathrm{~mm}^{3} / \mathrm{min}$ to $13,989 \mathrm{~mm}^{3} / \mathrm{min}$. Also Table 8 presents that the GRG in the wire EDM machining of DIN 1.2510 with optimum setting are effectively improved through this study. 
Table 7. The result of confirmation test

\begin{tabular}{|c|c|c|c|c|}
\hline & \multirow{2}{*}{ Initial } & \multicolumn{2}{|c|}{ Optimal Process Condition } & \multirow{3}{*}{ Improvemen } \\
\hline & & Prediction & Experiment & \\
\hline $\begin{array}{l}\text { Level of process } \\
\text { parameters }\end{array}$ & $\mathrm{AN}_{2} \mathrm{ON}_{2} \mathrm{SV}_{2} \mathrm{WF}_{2}$ & $\mathrm{AN}_{1} \mathrm{ON}_{3} \mathrm{SV}_{1} \mathrm{WF}_{2}$ & $\mathrm{AN}_{1} \mathrm{ON}_{3} \mathrm{SV}_{1} \mathrm{WF}_{2}$ & \\
\hline $\operatorname{Kerf}(\mu \mathrm{m})$ & 354 & & 345 & $\begin{array}{c}\text { decreased } \\
2.54 \%\end{array}$ \\
\hline $\begin{array}{l}\text { Material } \\
\text { Removal Rate } \\
\left(\mathrm{mm}^{3} / \mathrm{min}\right)\end{array}$ & 9,131 & & 13,989 & $\begin{array}{c}\text { increased } \\
53.20 \%\end{array}$ \\
\hline GRG & 0,4513 & 0,9690 & 0,6167 & $\begin{array}{c}\text { increased } \\
36.64 \%\end{array}$ \\
\hline
\end{tabular}

\section{Conclusion}

In this present paper, wire-EDM of DIN 1.2510 is carried out input parameters considered as arc on time, on time, servo voltage, and wire feed, and the response parameters as kerf and MRR. Taguchi's L9 orthogonal array design is used for performing wire EDM.

1) It was found that an arc on time of $2 \mathrm{~A}$, on time of $8 \mu \mathrm{s}$, servo voltage of $80 \mathrm{~V}$, and wire feed of $60 \mathrm{~mm} / \mathrm{min}$ is the optimal combination of input parameters.

2) ANOVA explained that pulse on time is the most influence parameter in effecting the response machining parameters.

3) The optimization using Taguchi combined grey relational analysis improved significantly the production of wire EDM of DIN 1.2510.

This research is supported financially by Grant of research for beginner lecturer, through letter of number decree of $0045 / \mathrm{E} 3 / \mathrm{LL} / 2018$, January $16^{\text {th }}$, 2018, Ministry of Research and Technology, DIKTI, The Republic of Indonesia and letter of number decree of 39/KP/LPKT-ITI/III/2018, March $29^{\text {th }}, 2018$, Institut Teknologi Indonesia and the authors would like to thank to BPPT BT MEPPO and Department of Mechanical Engineering, University of Indonesia.

\section{References}

1. N. Tosun, C. Cogun, G.Tosun, J. Mater. Process 152 (2004)

2. A. Goyal, J. King Saud Univ 29 (2017)

3. D. Suastiyanti, Ismojo, Int. J. Adv. Res 6 (2017)

4. C. F. Hu, Y. C. Zou, Y. W. Bao, J. Int. Ceramic 4 (2008)

5. D. Suastiyanti, S. Andayani, M.T.E. Manawan, Mater. Sci. and Eng 214 (2017)

6. D. Suastiyanti, W. Marlin, ARPN J. Eng, and Appl. 11 (2016)

7. R. Bobbili, V. Madhu, A. K. Gogia, Int. J. Eng and Tech. 18 (2015)

8. T. R. Newton, S. N. Melkote, T. R Watkins, R. M Trejo, L. Reister, J. Mater. Sci and Eng 513-514 (2009)

9. P. J. Ross, McGraw Hill, New York (1988)

10. G. Taguchi, Asian Productivity Organization (1990)

11. A. Ikram, N. A. Mufti, M. Q. Saleem, A. R. Khan, J. Mech. Sci. and Tech 27 (2013)

12. Deng. J, J. Grey Syst. 1 (1989)

13. S. Balasubramanian, S. Ganapathy, Int. J. Eng. Sci. and Tech 3 (2011)

14. D. C. Montgomery, 7th ed, New York, John Willey and Sons, Inc (2009)

15. S. H. Hsiang, Y. W. Lin, The Arabian J. Sci. and Eng 34 (2009) 